\title{
Adrenal vein sampling: technique and protocol, a systematic review
}

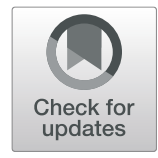

\author{
Keith B. Quencer(D)
}

\begin{abstract}
Primary aldosteronism is the leading cause of secondary hypertension worldwide. Its deleterious effects outstrip those due to blood pressure elevation alone. An essential part of the work-up of a patient with primary aldosteronism is determining if aldosterone production is unilateral or bilateral. With the former, surgery offers a potential cure and better overall outcomes. Adrenal vein sampling is considered the most reliable method to determine whether production is unilateral or bilateral. Sampling may be non-diagnostic when the vein cannot be properly cannulated. But with proper knowledge and experience as well as the utilization of certain techniques, procedure success can be high. Multiple protocols exist; their rationale and drawbacks are reviewed here. This article will give the reader an overview of techniques for improving procedural success as well as background, rationale and evidence to guide one in choosing the appropriate procedural and interpretation protocol.
\end{abstract}

Keywords: Primary aldosteronism, Aldosterone producing adenoma, Adrenal vein sampling, Cosyntropin

\section{Background}

The World Health Organization estimates that more than 1.3 billion people, nearly $31.3 \%$ of all adults, have hypertension (Mills et al. 2020). Hypertension is considered a leading cause of death and disability (Oparil et al. 2018). Primary aldosteronism (PA) is the most common cause of secondary hypertension, effecting an estimated $6 \%$ of all patients with hypertension and $20 \%$ of those with resistant hypertension (Byrd et al. 2018). Hyperaldosteronism causes hypertension via volume expansion due to sodium retention. Pathologic levels of serum aldosterone also exert pro-inflammatory and pro-fibrotic effects on the heart, blood vessels and kidneys (Brown 2013) leading to greater morbidity and mortality than essential hypertension, even when normalized for blood pressure elevation. This includes a $4.2 \mathrm{x}$ higher rate of stroke, 1.5x higher rate of renal damage, 2.6x higher rate of myocardial infarction and $5 x$ the rate of atrial fibrillation (Milliez et al. 2005; Rossi et al. 2006; Rossi et al. 2013; Savard et al. 2013).

Correspondence: keith.quencer@hsc.utah.edu

Department of Radiology, Division of Interventional Radiology, University of Utah, 50 North Medical Drive, Salt Lake City, UT 84132, USA
In current clinical practice, the diagnosis of primary hyperaldosteronism occurs in 2 stages. In properly selected patients (Table 1), screening is performed by measuring serum aldosterone and renin. The aldosterone: renin ratio (ARR) is then calculated. Values $>20$ are consistent with PA. Absolute values should also be evaluated as very low renin levels will potentially lead to a false positive test by exaggerating the ARR even in the setting of low aldosterone levels (Maiolino et al. 2017). After a positive screening test, confirmatory tests are often performed. Serum or urinary aldosterone levels are measured after sodium loading; persistent elevation confirms autonomous aldosterone secretion.

The next step, termed subtyping, is determining if production is unilateral or bilateral. In the former case, an aldosterone producing adenoma (APA) is the most likely cause with less likely etiologies being diffuse or nodular unilateral hyperplasia. Unilateral aldosterone production is most effectively treated with adrenalectomy. Bilateral production is termed idiopathic hyperplasia. Bilateral production is treated medically, utilizing mineralocorticoid receptor antagonists and, if needed, potassium sparing diuretics like amiloride. Spironolactone is a nonselective mineralocorticoid receptor (MR) antagonist
SpringerOpen

(c) The Author(s). 2021 Open Access This article is licensed under a Creative Commons Attribution 4.0 International License, which permits use, sharing, adaptation, distribution and reproduction in any medium or format, as long as you give appropriate credit to the original author(s) and the source, provide a link to the Creative Commons licence, and indicate if changes were made. The images or other third party material in this article are included in the article's Creative Commons licence, unless indicated otherwise in a credit line to the material. If material is not included in the article's Creative Commons licence and your intended use is not permitted by statutory regulation or exceeds the permitted use, you will need to obtain permission directly from the copyright holder. To view a copy of this licence, visit http://creativecommons.org/licenses/by/4.0/. 
Table 1 Indications for screening for PA

\author{
Resistant Hypertension* \\ Hypertension with a family hx of PA \\ Hypertension with a family hx of early onset HTN or stroke $(<40 \mathrm{y} / 0)$ \\ Hypertension with hypokalemia \\ Hypertension with adrenal adenoma \\ Hypertension with obstructive sleep apnea^
}

Guideline recommendations for screening of patients for primary aldosteronism. (Funder et al. 2016): *- Sustained BP > 150/100 mmHg without treatment, $>140 / 90 \mathrm{mmHg}$ on 3 antihypertensive drugs or $<140 / 90 \mathrm{mmHg}$ but requiring at least 4 antihypertensive drugs. In one study, 33.9\% of patients with obstructive sleep apnea were found to have PA (Di Murro et al. 2010)

which has anti-adrenergic effects potentially leading to gynecomastia and/or other sexual side effects. A more selective MR antagonist, eplerenone, can be used when spironolactone is not tolerated.

\section{Main text}

The recommended technique for lateralization of aldosterone production is adrenal vein sampling (AVS) (Funder et al. 2016; Rossi et al. 2014). The indications, protocols, techniques and outcomes are the subject of this review. For this manuscript, studies and trials published on adrenal vein sampling since 2015 were searched in PubMed. Twenty-one articles pertaining to technique and protocol during this time period were reviewed. Additionally, a search was performed for consensus guidelines and expert opinions since 2015. Three were reviewed and incorporated into this review. Additional articles published outside this time period were reviewed and cited, if relevant.

Computed tomography (CT) and AVS have a high rate of discordance in subtyping patients with PA. A metaanalysis in 2009, (Kempers et al. 2009), which included 38 studies and 950 patients, showed only a $62.2 \%$ concordance between cross sectional imaging and adrenal vein sampling (Table 2). The reasons for this

Table 2 Discordance between AVS and cross sectional imaging according to meta-analysis performed in 2009 which included 38 studies and 950 patients. (Kempers et al. 2009). In cases where $C T$ is non-lateralizing (either because both glands are normal or both glands are abnormal) but AVS is lateralizing, patients would have been inappropriately excluded from potentially curative surgery. In cases where CT suggests unilateral production but AVS shows bilateral production, patients would be subjected to inappropriate surgery. Finally, in cases where CT demonstrates unilateral pathology but AVS demonstrates contralateral pathology, these patients would have undergone wrong side surgery

\begin{tabular}{llll}
\hline Concordance & $\begin{array}{l}\text { CT bilateral, } \\
\text { AVS unilateral }\end{array}$ & $\begin{array}{l}\text { CT unilateral, } \\
\text { AVS bilateral }\end{array}$ & $\begin{array}{l}\text { CT and AVS } \\
\text { unilateral } \\
\text { but opposite }\end{array}$ \\
\hline $62.2 \%(591 / 950)$ & $19.2 \%(182 / 950)$ & $14.7 \%(140 / 950)$ & $3.9 \%(37 / 950)$ \\
\hline
\end{tabular}

discordance are legion. Cross sectional imaging (CT or magnetic resonance imaging-MRI) is insensitive in detecting sub-centimeter adrenal adenomas, which make up the majority of APAs. Additionally, both CT and MRI are insensitive to detect pathologically proven unilateral hyperplasia, which in one study was found to make up to $45 \%$ of cases unilateral production (Citton et al. 2015). Cross sectional imaging can be non-specific. Incidentally discovered adrenal adenomas are prevalent, seen by cross sectional imaging in about $1.9 \%$ of patients (Sherlock et al. 2020), the majority ( $\approx 90 \%)$ of which are considered non-functional. This relatively high prevalence of incidental adrenal adenomas limits the specificity of CT, especially in older patients who have a higher incidence of these adenomas (Kloos et al. 1997). Given the rarity of incidental adrenal lesions in young patients, the widely adopted Mayo Clinic protocol makes an exception to the recommendation for use of AVS to subtype PA in patients. Patients $<40$ years old who have a unilateral adrenal adenoma $>1 \mathrm{~cm}$ and a normal contralateral gland may proceed directly to adrenalectomy (Kupers et al. 2012). This exception has been called into question. For example, Citton et (Citton et al. 2015) al showed 2 failures of biochemical cure in patients $<40$ who underwent adrenalectomy based on cross sectional imaging alone. Ladurner (Ladurner et al. 2017) showed a 9.5\% (2/21) CT and AVS discordance in the under 40 subset of their study.

The proportion of patients with PA who have unilateral production determined by AVS differs by referral pattern and criteria used and is typically between $1 / 3 \mathrm{rd}$ and $2 / 3^{\text {rds }}$ of patients. Patients with more severe PA phenotype (i.e. spontaneous hypokalemia and/or higher aldosterone levels) are more likely to have an APA and therefore have unilateral production. While unilateral production can be effectively treated medically, patients who undergo AVS directed adrenalectomy have a high rate of biochemical cure (Table 3), a high rate of resolution of hypokalemia, potential for hypertension cure $(\approx 35 \%)$, lower hypertensive medication need, less

Table 3 Rate of biochemical PA cure cure after AVS guided adrenalectomy

\begin{tabular}{ll}
\hline Study & Rate of biochemical cure \\
\hline Umakoshi (Umakoshi et al. 2018) & $81.0 \%(187 / 231)$ \\
SPARTICUS (Dekkers et al. 2016) & $88.1 \%(37 / 42)$ \\
AVIS-2 (Rossi et al. 2019) & $93.8 \%(487 / 519)$ \\
Laurder (Ladurner et al. 2017) & $95.9 \%(142 / 148)$ \\
Lim (Lim et al. 2014) & $96.5 \%(112 / 116)$ \\
Citton (Citton et al. 2015) & $100 \%(56 / 56)$ \\
Pasternak (Pasternak et al. 2016) & $100 \%(45 / 45)$ \\
\hline
\end{tabular}


medication side effects and overall better quality of life (Rossi et al. 2019). Higher rates of hypertension cure after adrenalectomy are seen in patients with short duration hypertension, younger age, normal renal function female gender and normal body mass index (Funder et al. 2016; Rossi et al. 2014).

The SPRATICUS study (Dekkers et al. 2016) called into question need for AVS to subtype PA. Patients were triaged to surgical or medical treatment based either on AVS or CT; there were similar overall clinical results with no significant difference in the primary endpoint, the daily defined dose, which is a validated measure of total consumption of antihypertensive drugs to control blood pressure. Secondary endpoints such as hypertension cure and biochemical cure were not statistically different between the two groups but trends favoring he AVS arm were seen in these two outcomes. After adrenalectomy, biochemical persistence was seen in 5/46 patients (11\%) of the AVS subgroup compared to 9/46 (20\%) in the CT subgroup. Hypertension cure was seen in $10 / 46$ (22\%) in the AVS arm but only $4 / 46$ (9\%) in the CT arm. The study, however, was not powered to evaluate these secondary endpoints. This study had balanced randomization and had 92\% (184/200) 1-year clinical follow-up. Criticisms of the study included high percentage $(68 \%)$ of patients in the study with hypokalemia, which only occurs $9-37 \%$ of all patients with PA (Funder et al. 2016), which may limit the generalizability of the study. As aldosterone producing adenomas are seen in about $50 \%$ of PA patients with hypokalemia compared with only $20 \%$ of patients without hypokalemia, CT may be of greater utility in this more selected patient population who may have more APAs visible by CT (Rossi and Funder 2017). In this study, patients who underwent AVS also underwent CT as part of standard of care. Similar to results of multiple prior studies (see Table 2) there was a high rate of discordance between AVS and CT in SPARTICUS. That final clinical outcomes were similar between the two arms despite the high rate of discordance underlies potential issues and areas for improvement in subtyping both by $\mathrm{CT}$ and AVS.

Adrenal vein sampling may be non-diagnostic in a significant proportion of cases (Table 4). One study that highlighted this difficulty was the German Conn registry which included a total of 306 patients undergoing AVS. Diagnostic adequacy was achieved in only $41.1 \%$ of procedures (Vonend et al. 2011). But, with proper training, knowledge and experience it can be performed successfully Other studies since have shown a higher success rate. AVS is typically done at major referral centers (Rossi et al. 2014) and has a greater success in the hands of interventionalists experienced in this procedure. The learning curve is estimated to be about $20-30$ cases with maintenance of proficiency of about 15 annual cases (Jakobsson et al. 2018). In low volume centers, it may therefore be necessary to restrict AVS performance to a single dedicated interventional radiologist.

Nuclear medicine studies utilizing, including Iodine131 6-beta-iodomethyl-19-norcholesterol scintigraphy (NP-95) (Wu et al. 2019) and positron emission tomography imaging utilizing 11beta-hydroxylase 11Cmetomidate (MTO) (Bergstrom et al. 2000) are cumbersome to perform and have limited accuracy. They are not utilized in current clinical practice.

\section{Patient preparation}

Prior to AVS, all patients should undergo cross sectional imaging. This can rule out the rare cases of PA caused by adrenal cortical carcinoma, in which case adrenalectomy should be performed without the need for AVS. CT is preferred over MRI for three main reasons: 1 . CT better characterizes fat poor adenomas based on washout calculations (Seo et al. 2014), 2. CT has better spatial resolution and can better visualize small adrenal lesions, 3. It is more advantageous in pre-procedural planning.

Table 4 Success and Failure Rate of Recently Published AVS studies

\begin{tabular}{lllll}
\hline Study & Success rate & Failure R only & Failure L only & Failure B \\
\hline German Conn (Vonend et al. 2011) & $41.1(126 / 306)$ & $36.6(112 / 306)$ & $9.5(29 / 306)$ & $12.7(39 / 306)$ \\
Deipolyi (Deipolyi et al. 2015) & $63(58 / 92)$ & $30.4(28 / 92)$ & $2.1(2 / 92)$ & NR \\
Teng (Teng et al. 2015) & $55 \%(26 / 47)$ & $\mathrm{NR}(4 / 92)$ & $\mathrm{NR}$ \\
Page (Page et al. 2018) & $71.4 \%(105 / 147)$ & $23.1 \%(34 / 147)$ & $5.4 \%(8 / 147)$ & $0 / 147$ \\
Kocjan (Kocjan et al. 2020) & $77 \%(198 / 259)^{*}$ & $14 \%(33 / 235)^{*}$ & $3.8 \%(9 / 235)^{*}$ & $\mathrm{NR}$ \\
AVIS-2 (Rossi et al. 2019) & $80.1 \%(1302 / 1625)$ & $\mathrm{NR}$ & $\mathrm{NR}$ & $4.2 \%(2 / 48)$ \\
Lee (Lee et al. 2020) & $89.5 \%(43 / 48)$ & $6.3(3 / 48)$ & $0 \%(0 / 48)$ & 0 \\
Sparticus (Dekkers et al. 2016) & $95.8 \%(92 / 96)$ & $4.2 \%(4 / 96)$ & 0 & 0 \\
Ota (Ota et al. 2016) & $99.2 \%(124 / 125)$ & $0.8 \%(1 / 125)$ & 0 & 0 \\
\hline AVS
\end{tabular}

AVS success rates of published articles in last 10 years. ${ }^{*}$-This study variably reported success rates by procedure for overall and then by patient regarding left or right side. As $10 \%$ of patients had a repeat AVS, the reported right and left success rates differ from overall success. NR $=$ not reported. Success rates depend on the strictness of criteria used to define success (Lethielleux et al. 2015), which were not standardized across these studies 
CT visualizes the right adrenal vein in $93.2 \%$ of cases compared to $84.8 \%$ in MRI (Ota et al. 2016). This not only helps direct where to search during AVS but also identify anatomic variants, such as communication between the right adrenal and hepatic veins (Matsuura et al. 2008).

All patients should be willing surgical candidates prior to AVS. One study showed a $21.8 \% \%$ rate of patients lateralized by AVS who do not undergo surgery. AVS in these patients was a misuse of resources and was unnecessarily invasive (Ohno et al. 2020). Additionally, if there is a suspicion of familial PA, based on young age of onset, a strong family history of PA or a family history of strokes at a young age, types I and III should be ruled out prior to AVS as adrenalectomy is not indicated because bilateral secretion is the rule in these patients.

Drugs that interfere with the renin- angiotensinaldosterone system including angiotensin converting enzyme inhibitors, angiotensin receptor blockers, and mineralocorticoid receptor antagonists should be discontinued. As these drugs increase renin levels, bilateral adrenal cortex stimulation would occur, falsely decreasing the rate of lateralization. Literature is variable about the length of time these medications should be discontinued. Some suspend them for 2 weeks (Deipolyi et al. 2015), others discontinue these for 8 weeks (Lee et al. 2020) and still others also assess for suppressed plasma renin activity $(<0.6 \mathrm{ng} / \mathrm{ml} / \mathrm{hr})$ prior to proceeding with AVS (Kocjan et al. 2020). Doxazosin, hydralazine, diltiazem and nifedipine can be used as substitute antihypertensive agents. Patients should be told to institute an unrestricted sodium diet as low sodium diets lead to bilateral aldosterone secretion. Because discontinuing mineralocorticoid receptor blockers may lead to hypokalemic recidivism, serum potassium should be measured and, if $<3.5 \mathrm{mmol} / \mathrm{L}$ it should be corrected; low potassium inhibits aldosterone production and increases the proclivity of arrhythmias.

Pre-procedure clinic consultation with the interventionalist should be considered to ensure proper medications are held, potassium levels are checked and adequate replacement antihypertensives are being used. During this visit, personal and published rates of nondiagnostic studies and complications should be reviewed. If possible, the procedure should be scheduled in the morning when natural cortisol levels are highest.

\section{Procedure general}

There are many variations in how AVS is performed (Table 5).

\section{Cosyntropin Use}

One fundamental difference is whether synthetic adrenocorticotropic hormone (ACTH), known as cosyntropin, is used. The rationale for using cosyntropin is to increase cortisol secretion as well as to stabilize temporal

Table 5 Marked heterogeneity of basic procedural aspects of AVS

\begin{tabular}{|c|c|c|c|c|}
\hline Study & Cosyntropin use & $\begin{array}{l}\text { Sequential v } \\
\text { simultaneous }\end{array}$ & Selectivity index & Lateralization index \\
\hline SPARTICUS (Dekkers et al. 2016) & Cont. infusion & sequential & $\geq 3$ & $\geq 4.0 \mathrm{w} / \mathrm{CSI} \leq 1$ \\
\hline Deipolyi (Deipolyi et al. 2015) & Cont. infusion & sequential & $>3$ & $>4$ \\
\hline Kocjan (Kocjan et al. 2020) & Cont. infusion & sequential & $>5$ & $>4$ \\
\hline Pasternak (Pasternak et al. 2016) & Cont. infusion & sequential & NR & $\geq 4$ \\
\hline Ota (Ota et al. 2016) & Bolus $250 \mu \mathrm{g}$, sample 15 min later & Simultaneous & $\geq 5$ & $N R$ \\
\hline $\begin{array}{l}\text { Miotti (Citton et al. 2015; } \\
\text { Miotto et al. 2009) }\end{array}$ & No stim & Simultaneous & $\geq 1.1$ & $\geq 2.0$ \\
\hline Conn (Vonend et al. 2011) & No stim & Sequential & $\geq 2$ & $\geq 3$ \\
\hline Wolley (Wolley et al. 2015) & No stim & Sequential & $\geq 3$ & $\geq 2 \wedge$ with $C S I \leq 1$ \\
\hline $\begin{array}{l}\text { Lee (Lee et al. 2020) } \\
\text { Bellavance (Bouchard- } \\
\text { Bellavance et al. 2020) }\end{array}$ & Pre and post $250 \mathrm{mcg}$ bolus & Simultaneous & $\begin{array}{l}\geq 3 \text { Pre } \\
\geq 5 \text { Post }\end{array}$ & $\begin{array}{l}>2 \text { pre cosyntropin } \\
>4 \text { post cosyntropin }\end{array}$ \\
\hline Teng (Teng et al. 2015) & Pre and post (bolus + infusion) & Sequential & $\begin{array}{l}>2 \text { Pre cosyntropin } \\
>3 \text { Post cosyntropin }\end{array}$ & $\begin{array}{l}>3 \text { Pre cosyntropin } \\
>4 \text { Post cosyntropin }\end{array}$ \\
\hline Webb (Webb et al. 2012) & Pre and post (bolus + infusion) & Simultaneous & $>5$ & $>4$ \\
\hline $\begin{array}{l}\text { Japanese Endocrine } \\
\text { (Nishikawa et al. 2011) }\end{array}$ & $250 \mu \mathrm{g}$ cosyntropin bolus & Simultaneous & $\geq 5$ and $\geq 200 \mu \mathrm{g} / \mathrm{dl}$ cortisol & $\begin{array}{l}\geq 2.6 \text { or unilateral aldosterone } \\
\geq 14,000 \mathrm{pg} / \mathrm{ml}\end{array}$ \\
\hline Funder (Funder et al. 2016) & No conclusive rec & No conclusive rec & $\begin{array}{l}>5 \text { with cosyntropin } \\
>2 \text { without cosyntropin }\end{array}$ & $\begin{array}{l}>4 \text { with cosyntropin } \\
>2 \text { without cosyntropin }\end{array}$ \\
\hline $\begin{array}{l}\text { Expert Consensus } \\
\text { (Rossi et al. 2014) }\end{array}$ & No conclusive rec & No conclusive rec & $\begin{array}{l}\geq 3 \text { with cosyntropin } \\
\geq 2 \text { without cosyntropin }\end{array}$ & $\begin{array}{l}\geq 4 \text { with cosyntropin } \\
\geq 2 \text { without cosyntropin }\end{array}$ \\
\hline
\end{tabular}

$\mathrm{NR}=$ not reported. ^Wolley et al. used a modified lateralization index of (Dominant Adrenal Aldosterone/Cortisol)/(IVC Aldosterone/Cortisol) $\geq 2$ and a CSI $\leq 1$ 
fluctuation of both aldosterone and cortisol (Rossitto et al. 2020). After ACTH administration, adrenal vein cortisol levels increase by a factor of 5-10x while peripheral cortisol levels remain relatively stable. This increased step-up between adrenal and peripheral cortisol increases a ratio known as the selectivity index (SI) which is used to aver sampling adequacy (Table 6). Cosyntropin leads to a $4 \mathrm{x}$ increase in procedural "success", even when increasing the SI threshold from $2 \rightarrow 5$ (El Ghorayeb et al. 2016). A subset of patients in the Adrenal Vein International Study (AVIS)-2 study underwent AVS both pre and post cosyntropin stimulation, In these patients, there was significantly higher sampling adequacy $(81.3 \%)$, even using the strictest SI $(\geq 5)$, when compared to only $67.3 \%$ sampling adequacy in unstimulated patients with a low SI ( $\geq 2)$ (Rossitto et al. 2020). Additionally, cosyntropin may increase adrenal blood flow thereby enlarging the adrenal veins and making cannulation easier (Violari et al. 2019).

Cosyntropin use is not without potential disadvantages; it stimulates normal adrenal gland aldosterone production but has a varied, and sometimes minimal, effect on APA aldosterone production. This may lead to falsely non-lateralizing studies. There is a $22-25 \%$ increase in "bilateral" diagnoses in stimulated samples compared to unstimulated samples (Violari et al. 2019) (Teng et al. 2015). In both of these studies, patients were triaged to surgery based on pre-ACTH sampling and, even in patients whose post-ACTH was no longer lateralizing, biochemical cure was the rule. In the AVIS-2 study (Rossitto et al. 2020), 402 of their 1625 patients (24.7\%) had pre and post stimulation samples drawn. The authors estimated that, depending on exact indices used, approximately $32 \%$ of results would change from unilateral on pre-stimulation to bilateral on post stimulation. Cosyntropin may lead to other altered results. A study which performed sampling first without and then with a bolus of $250 \mu \mathrm{g}$ of cosyntropin highlighted this. A total of $28 \%$ (44/157) of patients had a different results comparing unstimulated and stimulated samples. While the majority $(72.7 \%(32 / 44))$ of these changes were lateralized without but bilateral with stimulation, 20.5\% (9/ 44) changed from being bilateral on basal study to being unilateral after stimulation and $6.8 \%(3 / 44)$ of cases lateralized to the opposite side and (El Ghorayeb et al. 2016).

\section{Procedural technique}

Right adrenal vein cannulation is the most difficult part of AVS; failure to cannulate the right adrenal vein is the most common cause of an unsuccessful procedure (see Table 4).

A solid understanding of the anatomy of the right adrenal vein is necessary for successful cannulation. It is small in diameter $(2-4 \mathrm{~mm})$ and short and most often enters the IVC at the T11/T12 interspace from a posterior-lateral direction. Other more subtle issues surrounding right adrenal vein anatomy are important to be aware of but are variably described in the literature. There are conflicting reports of the presence or absence of multiple adrenal veins. One study, which included 170 patients undergoing laparoscopic adrenalectomy for hyperaldosteronism, showed 4 duplications $(2.4 \%)$ and 1 triplication (0.6\%) (Scholten et al. 2013). This is in distinction to another study, utilizing CT (Matsuura et al. 2008), that showed no evidence of multiple adrenal veins $(0 / 79)$. If multiple adrenal veins are present, AVS may be misleading if the vein draining effluent from an APA is not sampled. This should be suspected if cortisol levels show the samples to be adequate but both adrenal veins show suppressed corrected aldosterone levels when compared with peripheral venous blood.

Another basic yet controversial anatomic topic is whether the right adrenal vein can share a common trunk with an accessory hepatic vein. In 800 AVS cases, Durant reported no venographic evidence of a common trunk between the adrenal vein and accessory hepatic veins. Communication between the adrenal vein and hepatic veins was seen by small capsular/superficial communicating veins in $0.25 \%(2 / 800)$ patients (Daunt 2005). On the other hand, other studies report a relative high frequency of direct communication between an accessory hepatic vein and the right adrenal vein. Matsuura (Matsuura et al. 2008) reported a 8\% (6/79) incidence by CT, Miotto (Miotto et al. 2009) reported a $12.1 \%(8 / 66)$ incidence by venography, and Ota (Ota et al. 2016) found a $16 \%(20 / 125)$ incidence by MR, CT and/or venography.

Table 6 Commonly used formulas in adrenal vein sampling

\begin{tabular}{lll}
\hline Description & Formula & Use \\
\hline Selectivity Index (SI) & "adrenal vein" cortisol/peripheral vein cortisol & Ascertain if sampling was adequate \\
Lateralization Index (LI) & $\begin{array}{l}\text { (dominant adrenal vein aldosterone } \div \text { cortisol)/ } \\
\text { (non-dominant adrenal vein aldosterone } \div \text { cortisol) }\end{array}$ & Determine if production is unilateral or bilateral \\
Contralateral Suppression Index (CSI) & $\begin{array}{l}\text { (Non-dominant adrenal vein aldosterone } \div \text { cortisol)/ } \\
\text { (peripheral aldosterone } \div \text { peripheral cortisol) }\end{array}$ & $\begin{array}{l}\text { Adjunct value to determine if production is } \\
\text { unilateral or bilateral }\end{array}$ \\
\hline
\end{tabular}


Multiple different catheters can be used to select the right adrenal vein. Caution is advised when using a reverse curved (e.g. Sim-2) catheter (Tan et al. 2020; Zelinka et al. 2012) as this may lead to too deep of cannulation, potentially beyond a tributary draining an APA. Deep cannulation can also increase the propensity for vein rupture or venous infarct.

Once a candidate right adrenal vein is cannulated, venogram is performed. Care must be taken to perform only gentle, slow and low volume injection to avoid rupture of the fragile adrenal veins. The adrenal gland has a varied venographic appearance (Fig. 1) with the only pathognomonic finding being an inferior emissary vein. The most common appearance of the right adrenal vein is a tangle of spidery vessels at the expected location of the adrenal gland. Capsular and superficial communicating veins communicating with phrenic, intercostal or renal capsular veins are common. In cases of ambiguous venographic appearance, rotational CT may be helpful (Deipolyi et al. 2015; Kocjan et al. 2020) (Fig. 2). Small accessory hepatic veins have a similar appearance but certain characteristics are useful to distinguish them from the adrenal vein (Fig. 3). Key among them is that injection of hepatic veins can lead to hepatic parenchymal staining, which is rarely seen in adrenal venography. This hepatic sinusoidal staining occurs without patient symptoms whereas, if one injects hard enough in an adrenal vein to cause an adrenal parenchymal stain, vague chest, flank or abdominal discomfort may occur.

After deciding the cannulated vein likely represents an adrenal vein, one should proceed with sampling. Gentle, intermittent or gravity assisted aspiration is preferred

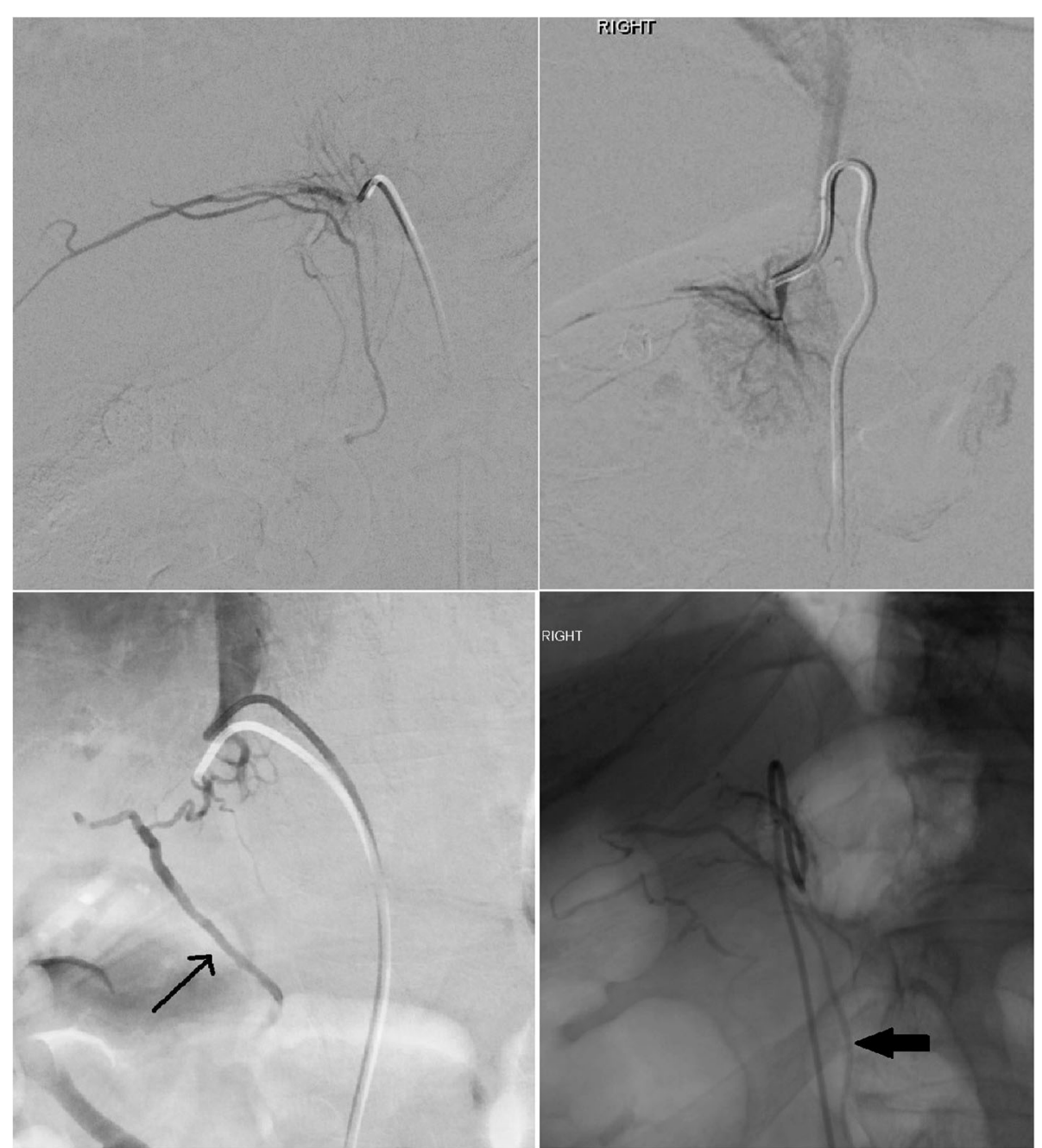

Fig. 1 Varied appearance of the right adrenal vein in 4 different patients. All 4 images are of the right adrenal vein, confirmed by elevated cortisol levels. Images c and $\mathbf{d}$ show an inferior emissary vein (black arrows), diagnostic of adrenal vein cannulation 


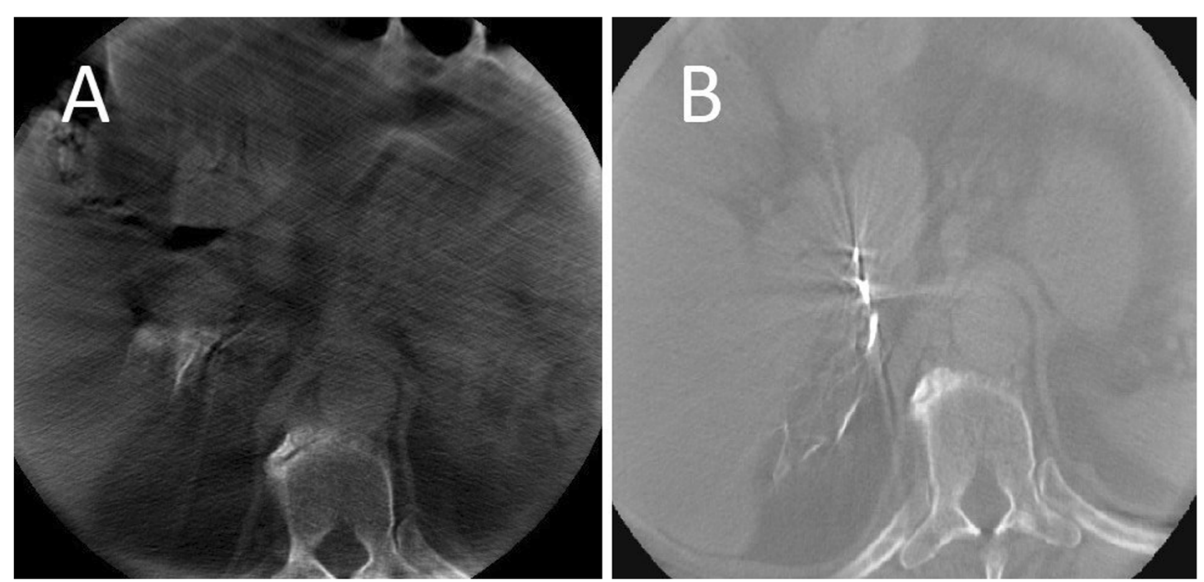

Fig. 2 Cone-beam CT of an accessory hepatic vein (a) and the right adrenal vein (b). In this patient, two different veins were cannulated. Given ambiguous conventional venographic appearance, cone-beam CT was performed. a Shows opacification of hepatic parenchyma. b Confirms cannulation of the adrenal vein

over high negative pressure aspiration which may collapse the adrenal vein and prevent venous sampling. The first 2 cc of aspirated fluid should be wasted as iodinated contrast has been shown to interfere with measurement of serum aldosterone levels. A side hole placed $3 \mathrm{~mm}$ from the tip of the catheter is generally recommended to improve flow through the catheter. This may also decrease the risk of venous thrombosis as the catheter is less occlusive within the adrenal vein. One may also place a 0.018 " wire through the 5 Fr catheter to allow for centering of the catheter within the right adrenal vein; aspiration is then done through the side arm of a rotating hemostatic valve (Mailhot et al. 2015). Confirmatory venogram after sampling is recommended to ensure that the catheter has not changed positions.

\section{Left adrenal}

In sequential AVS, the right adrenal vein cannulation, which is more time consuming than the left, should be done first thereby decreasing the time gap between samplings. The left adrenal vein has a constant anatomic position and joins the inferior phrenic vein to form a variable length phrenic adrenal trunk before entering the cranial aspect of the left renal vein (Fig. 4). There are many catheters and methods of left adrenal vein; one simple way is to select the left renal vein using a Simmons- 2 catheter. The catheter is then pulled down, initially causing the tip to enter further into the left renal vein. Eventually, further catheter retraction will start pulling the catheter back and the catheter tip will "jump" up just lateral to the spine to engage the phrenic adrenal trunk.

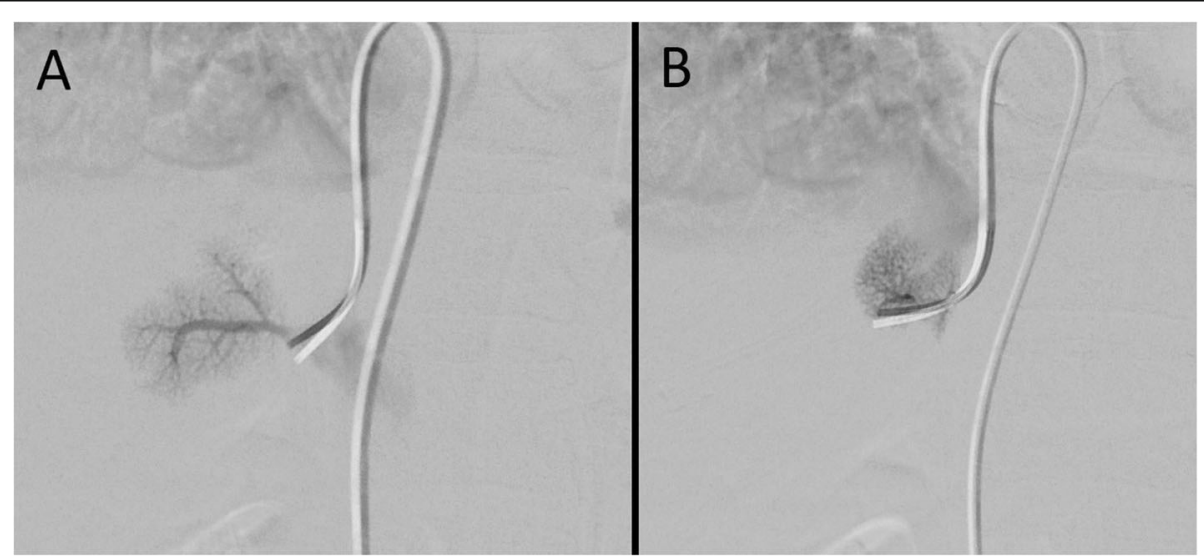

Fig. 3 Venographic appearance of an accessory hepatics vein. Images A + B, taken in the same patient show two different accessory hepatic veins. The parenchymal staining and lack of capsular/communicating veins are consistent with hepatic vein rather than adrenal vein cannulation. Occasionally, one may see intrahepatic communication to larger hepatic veins 


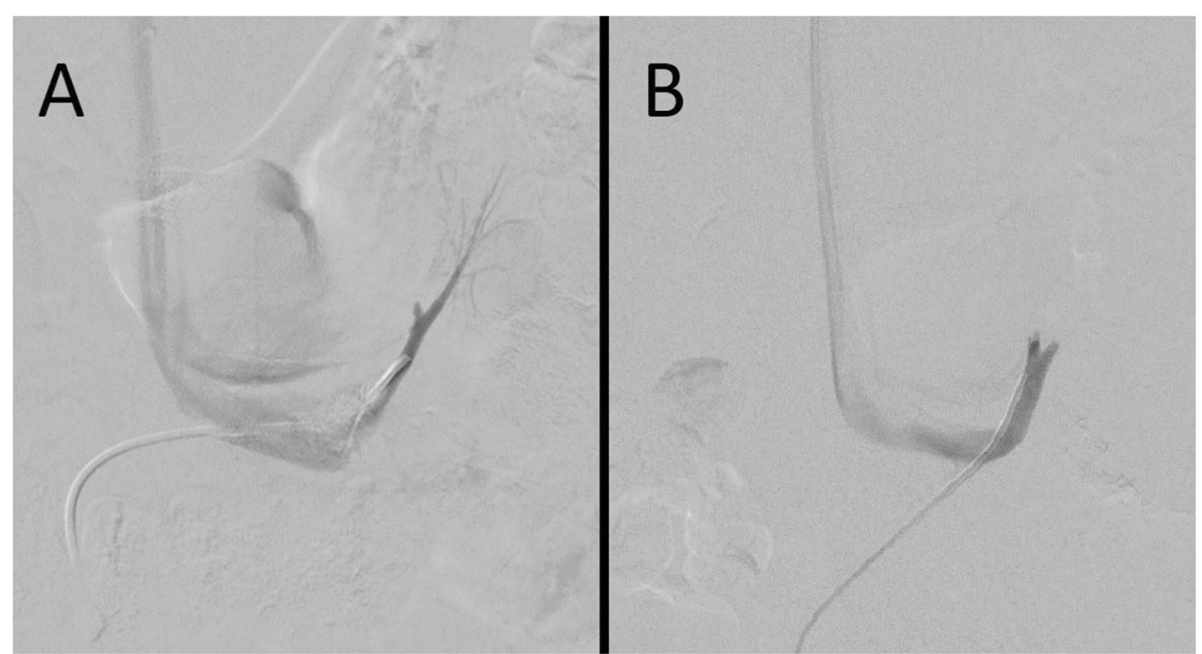

Fig. 4 Venographic appearance of the left adrenal vein. In both A + B a Simmons-2 catheter is used to select the left renal vein and then the common phrenic adrenal trunk. In $\mathbf{a}$, contrast refluxes into the adrenal branch (lateral). In $\mathbf{b}$, the common trunk and a small part of the inferior phrenic vein (medial) and the left adrenal vein (lateral) are seen. Reflux of contrast into the adrenal vein proper is not necessary to confirm correct location

Most operators sample from this common trunk. Some, including the Japanese endocrine society, advocate for selective engagement the left adrenal vein branch (Kocjan et al. 2020; Lupi et al. 2019; Nishikawa et al. 2011; Ota et al. 2016; Rossi et al. 2014). But, selective sampling may lead to accidental sampling beyond an aldosterone rich tributary, adds cost to the procedure given the need for a microcatheter and microwire). Additionally, sampling in the left adrenal vein proper may predispose to thrombosis or to vessel rupture during injection. One small study of 22 patients (Takada et al. 2013) compared sampling from the adrenal vein proper and the common phrenic adrenal trunk. While absolute aldosterone and cortisol levels increased, the $\mathrm{A} / \mathrm{C}$ ratio and overall results did not significantly change. Therefore, sampling in the common trunk is recommended.

\section{Interpretation of results (Table 7)}

\section{Adequacy}

As cortisol is produced solely by the adrenal glands, cortisol gradient between the peripheral veins and "adrenal" vein is used to confirm adequate adrenal vein cannulation. There is a wide variety $(\geq 1.1$ to $\geq 5)$ of selectivity indices used to determine sampling adequacy (see Table 5). Selectivity indices $>2$ and $>5$ are generally used as cutoffs for adequacy with unstimulated and stimulated sampling, respectively. These existing guidelines have been called into question. The AVIS-2 analysis (Rossitto et al. 2020) showed similarity of specimen adequacy with unstimulated SI of $\geq 1.4$ and stimulated SI of $\geq 5$ suggesting that a more permissive SI for unstimulated samples may be indicated.

\section{Lateralization}

Lateralization indices of $>2$ for unstimulated and $>4$ for stimulated sampling are recommended by the endocrine society (Funder et al. 2016). One study of stimulated AVS (Umakoshi et al. 2018), showed that biochemical cure was only achieved in $64.2 \%(29 / 47)$ of patients with an LI between 2 and 4 but a $80.9 \%(187 / 231)$ biochemical cure in patients in patients with LI $>4$. The PASO study (Williams et al. 2017) and a multicenter Japanese study (Umakoshi et al. 2018) also showed that higher LIs correlated with significantly higher clinical and biochemical success rates after adrenalectomy. The contralateral suppression index may be helpful adjunctive lateralizing data. One study (Wolley et al. 2015) showed that $82.5 \%$ $(66 / 80)$ of patients who lateralized by LI also had

Table 7 Results from AVS in a 31y/o female with a history of hypertension and hypokalemia who was found to have PA by ARR (237). CT (not shown) showed normal appearing bilateral adrenal glands. Samples were taken with continuous cosyntropin infusion at $50 \mu \mathrm{g} / \mathrm{hr}$. Left sided sampling was done in the common phrenic adrenal trunk. Ratios between the adrenal vein cortisol and IVC cortisol, the SI, are used to determine sampling adequacy. In this case $\mathrm{SI}$ on the right is 38.1 (914/24) and 6.6 (159/24) on the left, the latter number lower because of dilution from the inferior phrenic vein. The lateralization index is 20 (7.2/.35) with a CSI of 0.16 (.35/2.2). The patient underwent left adrenalectomy with hypertension and biochemical cure

\begin{tabular}{llll}
\hline & Aldosterone $(\mathbf{n g} / \mathbf{d l})$ & Cortisol $(\boldsymbol{\mu g} / \mathbf{d} \mathbf{l})$ & $\mathbf{A} / \mathbf{C}$ ratio \\
\hline Right Adrenal Vein & 319 & 914 & 0.35 \\
Left Adrenal Vein & 1144 & 159 & 7.2 \\
Inferior Vena Cava & 52 & 24 & 2.2 \\
\hline
\end{tabular}


concurrent CSI $<1$. This subset of patients had a higher rate of hypertension and biochemical cure (40.9\%; 27/66 and $98 \% ; 48 / 49)$ respectively compared to those who met traditional LI criteria but whose CSI was > 1 (14.3\%; $2 / 14$ and $55.6 \% 5 / 9)$. As medical therapy is effective in cases of unilateral disease but surgery is ineffective in bilateral disease, meeting the additional condition of contralateral supression prior to adrenalectomy may be prudent.

\section{AVS limitations}

AVS is only offered at a limited number of referral centers making it relative inaccessible and underutilized. Missed opportunities for adrenalectomy or non -AVS guided adrenalectomy often occur (Funder 2012; Rossi 2007). In the AVIS-2 study, 23.6\% (160/679) of patients underwent adrenalectomy without AVS guidance.

Then, a significant portion of procedures are nondiagnostic (see Table 4). In cases of unilateral sampling failure, useful information may still be gleaned. Pasternak et al. (Pasternak et al. 2016) showed 100\% specificity and $50 \%$ sensitivity to be able to lateralize patients with unilateral data using the formula [(unilateral adrenal vein aldosterone $\div$ cortisol)/(IVC aldosterone $\div$ cortisol)] . A value $>5.5$ accurately predicted ipsilateral production while values $<0.5$ predicted contralateral production. Values in between contained cases of both bilateral and unilateral secretion. Similar high specificity but low sensitivity results have been shown in other studies (Lin et al. 2019).

AVS may lead to complications. While older publications describe a high (10\%) rate of complications, including venous rupture, adrenal infarction and hypertensive crisis, subsequent publications have shown complications to be rare (Daunt 2005). In the largest published multicenter observational studies to date, the complication rate was $0.61 \%(16 / 2604)$ (Rossi et al. 2012). This decreasing rate of complications is likely due to the growing understanding that venography should be gentle and low volume. Catheter induced adrenal vein thrombosis may also occur if an occlusive catheter left in situ for a prolonged period, therefore, some recommend administration of IV heparin at the start of the procedure (Kahn and Angle 2010).

While cortisol is used both as a marker of adrenal vein selection and as a way to normalize aldosterone levels by accounting for dilution, cortisol can be pathologically co-secreted in a small percentage of aldosterone adenomas. This co-secretion may lead to false bilateral results as the corrected aldosterone level (A/C ratio) on the side of the co-secreting APA will be low. In cases where cortisol co-secretion is suspected, one may use another adrenal marker, such as metanepherines (Goupil et al. 2015).
Finally, the marked variety of protocols and indices leads to variable subtype classification, treatments and outcomes. In a study by Klein et al. (Kline et al. 2008), only $17 \%(11 / 63)$ patients would be classified the same across the all the various protocols and indices. Lethielleux et al. (Lethielleux et al. 2015) repeated a similar analysis by retrospectively analyzing data from 537 nonstimulated simultaneous AVS procedures. They found that there is a $4.5 \mathrm{x}$ difference in sample inadequacy using the most lenient $(\geq 1.1)$ versus most strict $(\geq 3)$ SI $(4 \%(19 / 537)$ vs $18 \%(99 / 537))$. They also found that while $58.2 \%(313 / 537)$ of patients would meet criteria for unilateral lateralization (with $\mathrm{LI} \geq 2$ ), only $25.8 \%(139 / 537)$ would be classified as unilateral utilizing the combined modified lateralization index [(Dominant side Aldosterone $\div$ Cortisol ratio)/ (Inferior Vena Cava Aldosterone $\div$ Cortisol)] $\geq 2$ with concomitant $\mathrm{CSI}<1$ suggested by the group from the University of Queensland (Stowasser et al. 2001). Further research is needed to determine what protocol and indices should be used.

\section{Conclusions}

PA is a common disease whose ill effects are beyond elevation of blood pressure. AVS is done to determine if aldosterone production is unilateral or bilateral. Surgery is generally preferred in the former while medical treatment is utilized in the latter. Non-diagnostic adrenal vein sampling can be minimized with proper provider training, experience and knowledge as well as selective use of rotational CT and real time rapid cortisol assays. Understanding the advantages and disadvantages of the wide variety of different protocols is important in optimizing AVS performance.

\section{Abbreviations \\ PA: Primary aldosteronism; ARR: Aldosterone to renin ratio; APA: Aldosterone producing adenoma; MR: Mineralocorticoid receptor; AVS: Adrenal vein sampling; CT: Computed tomography; MRI: Magnetic resonance imaging; LI: Lateralization index; ACTH: Adrenocorticotropic hormone; SI: Selectivity index; CSI: Contralateral suppression index; A/C ratio: Aldosterone to cortisol ratio}

\section{Acknowledgements \\ None.}

\section{Author's contributions}

$\mathrm{KQ}$ was responsible for the conception and writing of this manuscript. The author(s) read and approved the final manuscript.

\section{Funding}

None.

Availability of data and materials

Systematic review of published literature. All articles used cited in bibliography.

\section{Declarations}

Ethics approval and consent to participate Not applicable. 


\section{Consent for publication}

Not applicable.

\section{Competing interests}

None.

Received: 20 January 2021 Accepted: 10 March 2021

Published online: 01 April 2021

\section{References}

Bergstrom M, Juhlin C, Bonasera TA, Sundin A, Rastad J, Akerstrom G, Langstrom B (2000) PET imaging of adrenal cortical tumors with the 11 beta-hydroxylase tracer 11C-metomidate. J Nucl Med 41(2):275-282 Retrieved from https:// www.ncbi.nlm.nih.gov/pubmed/10688111

Bouchard-Bellavance R, Perrault F, Soulez G, Chagnon M, Kline GA, Bourdeau I, Lacroix A, So B, Therasse E (2020) Adrenal vein sampling: external validation of multinomial regression modelling and left adrenal vein-to-peripheral vein ratio to predict lateralization index without right adrenal vein sampling. Clin Endocrinol 93(6):661-671. https://doi.org/10.1111/cen.14295

Brown NJ (2013) Contribution of aldosterone to cardiovascular and renal inflammation and fibrosis. Nat Rev Nephrol 9(8):459-469. https://doi.org/10.1 038/nrneph.2013.110

Byrd JB, Turcu AF, Auchus RJ (2018) Primary aldosteronism: practical approach to diagnosis and management. Circulation 138(8):823-835. https://doi.org/10.11 61/CIRCULATIONAHA.118.033597

Citton M, Viel G, Rossi GP, Mantero F, Nitti D, lacobone M (2015) Outcome of surgical treatment of primary aldosteronism. Langenbeck's Arch Surg 400(3): 325-331. https://doi.org/10.1007/s00423-014-1269-4

Daunt N (2005) Adrenal vein sampling: how to make it quick, easy, and successful. Radiographics 25(Suppl 1):S143-S158. https://doi.org/10.1148/rg.2 5 si055514

Deipolyi AR, Bailin A, Wicky S, Alansari S, Oklu R (2015) Adrenal vein sampling for Conn's syndrome: diagnosis and clinical outcomes. Diagnostics (Basel) 5(2): 254-271. https://doi.org/10.3390/diagnostics5020254

Dekkers T, Prejbisz A, Kool LJS, Groenewoud H, Velema M, Spiering W et al (2016) Adrenal vein sampling versus $C T$ scan to determine treatment in primary aldosteronism: an outcome-based randomised diagnostic trial. Lancet Diabetes Endocrinol 4(9):739-746. https://doi.org/10.1016/S2213-8587(16)301 00-0

Di Murro A, Petramala L, Cotesta D, Zinnamosca L, Crescenzi E, Marinelli C et al (2010) Renin-angiotensin-aldosterone system in patients with sleep apnoea: prevalence of primary aldosteronism. J Renin-Angiotensin-Aldosterone Syst 11(3):165-172. https://doi.org/10.1177/1470320310366581

El Ghorayeb N, Mazzuco TL, Bourdeau I, Mailhot JP, Zhu PS, Therasse E, Lacroix A (2016) Basal and post-ACTH aldosterone and its ratios are useful during adrenal vein sampling in primary aldosteronism. J Clin Endocrinol Metab 101(4):1826-1835. https://doi.org/10.1210/jc.2015-3915

Funder JW (2012) Primary aldosteronism: clinical lateralization and costs. J Clin Endocrinol Metab 97(10):3450-3452. https://doi.org/10.1210/jc.2012-3046

Funder JW, Carey RM, Mantero F, Murad MH, Reincke M, Shibata H, Stowasser M, Young WF Jr (2016) The management of primary aldosteronism: case detection, diagnosis, and treatment: an endocrine society clinical practice guideline. J Clin Endocrinol Metab 101(5):1889-1916. https://doi.org/10.1210/jc.2015-4061

Goupil R, Wolley M, Ungerer J, McWhinney B, Mukai K, Naruse M, Gordon RD, Stowasser M (2015) Use of plasma metanephrine to aid adrenal venous sampling in combined aldosterone and cortisol over-secretion. Endocrinol Diabetes Metab Case Rep 2015:150075. https://doi.org/10.1530/EDM-15-0075

Jakobsson H, Farmaki K, Sakinis A, Ehn O, Johannsson G, Ragnarsson O (2018) Adrenal venous sampling: the learning curve of a single interventionalist with 282 consecutive procedures. Diagn Interv Radiol 24(2):89-93. https://doi. org/10.5152/dir.2018.17397

Kahn SL, Angle JF (2010) Adrenal vein sampling. Tech Vasc Interv Radiol 13(2): 110-125. https://doi.org/10.1053/j.tvir.2010.02.006

Kempers MJ, Lenders JW, van Outheusden L, van der Wilt GJ, Schultze Kool LJ, Hermus AR, Deinum J (2009) Systematic review: diagnostic procedures to differentiate unilateral from bilateral adrenal abnormality in primary aldosteronism. Ann Intern Med 151(5):329-337. https://doi.org/10.7326/ 0003-4819-151-5-200909010-00007

Kline GA, Harvey A, Jones C, Hill MH, So B, Scott-Douglas N, Pasieka JL (2008) Adrenal vein sampling may not be a gold-standard diagnostic test in primary aldosteronism: final diagnosis depends upon which interpretation rule is used. Variable interpretation of adrenal vein sampling. Int Urol Nephrol 40(4):1035-1043. https://doi.org/10.1007/s11255-008-9441-9

Kloos RT, Korobkin M, Thompson NW, Francis IR, Shapiro B, Gross MD (1997) Incidentally discovered adrenal masses. Cancer Treat Res 89:263-292. https:// doi.org/10.1007/978-1-4615-6355-6_13

Kocjan T, Jensterle M, Vidmar G, Vrckovnik R, Berden P, Stankovic M (2020) Adrenal vein sampling for primary aldosteronism: a 15-year national referral center experience. Radiol Oncol 54(4):409-418. https://doi.org/10.2478/raon-2020-0052

Kupers EM, Amar L, Raynaud A, Plouin PF, Steichen O (2012) A clinical prediction score to diagnose unilateral primary aldosteronism. J Clin Endocrinol Metab 97(10):3530-3537. https://doi.org/10.1210/jc.2012-1917

Ladurner R, Sommerey S, Buechner S, Dietz A, Degenhart C, Hallfeldt K, Gallwas J (2017) Accuracy of adrenal imaging and adrenal venous sampling in diagnosing unilateral primary aldosteronism. Eur J Clin Investig 47(5):372377. https://doi.org/10.1111/eci.12746

Lee J, Kang B, Ha J, Kim MH, Choi B, Hong TH, Kang MIL, Lim DJ (2020) Clinical outcomes of primary aldosteronism based on lateralization index and contralateral suppression index after adrenal venous sampling in real-world practice: a retrospective cohort study. BMC Endocr Disord 20(1):114. https:// doi.org/10.1186/s12902-020-00591-8

Lethielleux G, Amar L, Raynaud A, Plouin PF, Steichen O (2015) Influence of diagnostic criteria on the interpretation of adrenal vein sampling. Hypertension 65(4):849-854. https://doi.org/10.1161/HYPERTENSIONAHA.114.04812

Lim V, Guo Q, Grant CS, Thompson GB, Richards ML, Farley DR, Young WF Jr (2014) Accuracy of adrenal imaging and adrenal venous sampling in predicting surgical cure of primary aldosteronism. J Clin Endocrinol Metab 99(8):2712-2719. https://doi.org/10.1210/jc.2013-4146

Lin L, Zhou L, Guo Y, Liu Z, Chen T, Liu Z, Wang K, Li J, Zhu Y, Ren Y (2019) Can incomplete adrenal venous sampling data be used in predicting the subtype of primary aldosteronism? Ann Endocrinol (Paris) 80(5-6):301-307. https:// doi.org/10.1016/j.ando.2019.10.001

Lupi A, Battistel M, Barbiero G, Miotto D, Rossi GP, Quaia E (2019) Simultaneous bilateral adrenal vein sampling for primary aldosteronism: useful tips to make it simple and safe. Eur Radiol 29(11):6330-6335. https://doi.org/10.1007/s0033 0-019-06209-5

Mailhot JP, Traistaru M, Soulez G, Ladouceur M, Giroux MF, Gillbert P, Zhu PS, Bourdeau I Oliva VL, Lacroix A, Therasse E (2015) Adrenal vein sampling in primary aldosteronism: sensitivity and specificity of basal adrenal vein to peripheral vein cortisol and aldosterone ratios to confirm catheterization of the adrenal vein. Radiology 277(3): 887-894. https://doi.org/10.1148/radiol.2015142413

Maiolino G, Rossitto G, Bisogni V, Cesari M, Seccia TM, Plebani M et al (2017) Quantitative value of aldosterone-renin ratio for detection of aldosterone-producing adenoma: the aldosterone-renin ratio for primary aldosteronism (AQUARR) study. J Am Heart Assoc 6(5). https://doi.org/10.1161/JAHA.117.005574

Matsuura T, Takase K, Ota H, Yamada T, Sato A, Satoh F, Takahashi S (2008) Radiologic anatomy of the right adrenal vein: preliminary experience with MDCT. AJR Am J Roentgenol 191(2):402-408. https://doi.org/10.2214/AJR.07.3338

Milliez P, Girerd X, Plouin PF, Blacher J, Safar ME, Mourad JJ (2005) Evidence for an increased rate of cardiovascular events in patients with primary aldosteronism. J Am Coll Cardiol 45(8):1243-1248. https://doi.org/10.1016/j.ja cc.2005.01.015

Mills KT, Stefanescu A, He J (2020) The global epidemiology of hypertension. Nat Rev Nephrol 16(4):223-237. https://doi.org/10.1038/s41581-019-0244-2

Miotto D, De Toni R, Pitter G, Seccia TM, Motta R, Vincenzi M et al (2009) Impact of accessory hepatic veins on adrenal vein sampling for identification of surgically curable primary aldosteronism. Hypertension 54(4):885-889. https:// doi.org/10.1161/HYPERTENSIONAHA.109.134759

Nishikawa T, Omura M, Satoh F, Shibata H, Takahashi K, Tamura N et al (2011) Guidelines for the diagnosis and treatment of primary aldosteronism--the Japan endocrine society 2009. Endocr J 58(9):711-721. https://doi.org/10.1 507/endocrj.ej11-0133

Ohno Y, Naruse M, Beuschlein F, Schreiner F, Parasiliti-Caprino M, Deinum J Drake WM, Fallo F, Fuss CT, Grytaas MA, Ichijo T, Inagaki N, Kakutani M, Kastelan D, Kraljevic I, Katabami T, Kocjan T, Monticone S, Mulatero P, O'Toole S, Kobayashi H, Sone M, Tsuiki M, Wada N, Williams TA, Reincke M, Tanabe A (2020) Adrenal venous sampling guided adrenalectomy rates in primary aldosteronism: results of an international cohort (AVSTAT). J Clin Endocrinol Metab 106(3):e1400-e1407. https://doi.org/10.1210/clinem/dgaa706

Oparil S, Acelajado MC, Bakris GL, Berlowitz DR, Cifkova R, Dominiczak AF et al (2018) Hypertension. Nat Rev Dis Primers 4(1):18014. https://doi.org/10.1038/ nrdp.2018.14 
Ota H, Seiji K, Kawabata M, Satani N, Omata K, Ono Y, Iwakura Y, Morimoto R, Matsuura T, Kudo M, Tominaga J, Satoh F, Ito S, Takase K (2016) Dynamic multidetector $C T$ and non-contrast-enhanced MR for right adrenal vein imaging: comparison with catheter venography in adrenal venous sampling. Eur Radiol 26(3):622-630. https://doi.org/10.1007/s00330-015-3872-3

Page MM, Taranto M, Ramsay D, van Schie G, Glendenning P, Gillett MJ, Vasikaran SD (2018) Improved technical success and radiation safety of adrenal vein sampling using rapid, semi-quantitative point-of-care cortisol measurement. Ann Clin Biochem 55(5):588-592. https://doi.org/10.1177/0004563218760352

Pasternak JD, Epelboym I, Seiser N, Wingo M, Herman M, Cowan V, Gosnell JE, Shen WT, Kerlan RK Jr, Lee JA, Duh QY, Suh I (2016) Diagnostic utility of data from adrenal venous sampling for primary aldosteronism despite failed cannulation of the right adrenal vein. Surgery 159(1):267-273. https://doi. org/10.1016/j.surg.2015.06.048

Rossi GP (2007) New concepts in adrenal vein sampling for aldosterone in the diagnosis of primary aldosteronism. Curr Hypertens Rep 9(2):90-97. https:// doi.org/10.1007/s11906-007-0017-3

Rossi GP, Auchus RJ, Brown M, Lenders JW, Naruse M, Plouin PF et al (2014) An expert consensus statement on use of adrenal vein sampling for the subtyping of primary aldosteronism. Hypertension 63(1):151-160. https://doi. org/10.1161/HYPERTENSIONAHA.113.02097

Rossi GP, Barisa M, Allolio B, Auchus RJ, Amar L, Cohen D, Degenhart C, Deinum J, Fischer E, Gordon R, Kickuth R, Kline G, Lacroix A, Magill S, Miotto D, Naruse M, Nishikawa T, Omura M, Pimenta E, Plouin PF, Quinkler M, Reincke M, Rossi E, Rump LC, Satoh F, Schultze Kool L, Seccia TM, Stowasser M, Tanabe A, Trerotola S, Vonend O, Widimsky J Jr, Wu KD, Wu VC, Pessina AC (2012) The adrenal vein sampling international study (AVIS) for identifying the major subtypes of primary aldosteronism. J Clin Endocrinol Metab 97(5):1606-1614. https://doi.org/10.1210/jc.2011-2830

Rossi GP, Bernini G, Desideri G, Fabris B, Ferri C, Giacchetti G et al (2006) Renal damage in primary aldosteronism: results of the PAPY study. Hypertension 48(2):232-238. https://doi.org/10.1161/01.HYP.0000230444.01215.6a

Rossi GP, Cesari M, Cuspidi C, Maiolino G, Cicala MV, Bisogni V, Mantero F, Pessina AC (2013) Long-term control of arterial hypertension and regression of left ventricular hypertrophy with treatment of primary aldosteronism. Hypertension 62(1):62-69. https://doi.org/10.1161/HYPERTENSIONAHA.113.01316

Rossi GP, Funder JW (2017) Adrenal venous sampling versus computed tomographic scan to determine treatment in primary aldosteronism (the SPARTACUS trial): a critique. Hypertension 69(3):396-397. https://doi.org/10.11 61/HYPERTENSIONAHA.116.08820

Rossi GP, Rossitto G, Amar L, Azizi M, Riester A, Reincke M, Degenhart C, Widimsky J Jr, Naruse M, Deinum J, Schultze Kool L, Kocjan T, Negro A, Rossi E, Kline G, Tanabe A, Satoh F, Christian Rump L, Vonend O, Willenberg HS, Fuller PJ, Yang J, Chee NYN, Magill SB, Shafigullina Z, Quinkler M, Oliveras A, Dun Wu K, Wu VC, Kratka Z, Barbiero G, Battistel M, Chang CC, Vanderriele PE, Pessina AC (2019) Clinical outcomes of 1625 patients with primary aldosteronism subtyped with adrenal vein sampling. Hypertension 74(4):800808. https://doi.org/10.1161/HYPERTENSIONAHA.119.13463

Rossitto G, Amar L, Azizi M, Riester A, Reincke M, Degenhart C, Widimsky J Jr, Naruse M, Deinum J, Schultzekool L, Kocjan T, Negro A, Rossi E, Kline G, Tanabe A, Satoh F, Rump LC, Vonend O, Willenberg HS, Fuller P, Yang J, Nian Chee NY, Magill SB, Shafigullina Z, Quinkler M, Oliveras A, Chang CC, Wu VC, Somloova Z, Maiolino G, Barbiero G, Battistel M, Lenzini L, Quaia E, Pessina AC, Rossi GP (2020) Subtyping of primary aldosteronism in the AVIS-2 study: assessment of selectivity and lateralization. J Clin Endocrinol Metab 105(6): 2042-2052. https://doi.org/10.1210/clinem/dgz017

Savard S, Amar L, Plouin PF, Steichen O (2013) Cardiovascular complications associated with primary aldosteronism: a controlled cross-sectional study. Hypertension 62(2): 331-336. https:/doi.org/10.1161/HYPERTENSIONAHA.113.01060

Scholten A, Cisco RM, Vriens MR, Shen WT, Duh QY (2013) Variant adrenal venous anatomy in 546 laparoscopic adrenalectomies. JAMA Surg 148(4):378-383. https://doi.org/10.1001/jamasurg.2013.610

Seo JM, Park BK, Park SY, Kim CK (2014) Characterization of lipid-poor adrenal adenoma: chemical-shift MRI and washout CT. AJR Am J Roentgenol 202(5): 1043-1050. https://doi.org/10.2214/AJR.13.11389

Sherlock M, Scarsbrook A, Abbas A, Fraser S, Limumpornpetch P, Dineen R, Stewart PM (2020) Adrenal Incidentaloma. Endocr Rev 41(6):775-820. https:// doi.org/10.1210/endrev/bnaa008

Stowasser M, Gordon RD, Rutherford JC, Nikwan NZ, Daunt N, Slater GJ (2001) Diagnosis and management of primary aldosteronism. J Renin-AngiotensinAldosterone Syst 2(3):156-169. https://doi.org/10.3317/jraas.2001.022
Takada A, Suzuki K, Mori Y, Hyodo R, Kawakami K, Okochi Y, Naganawa S (2013) Comparison of the central adrenal vein and the common trunk of the left adrenal vein for adrenal venous sampling. J Vasc Interv Radiol 24(4):550-557. https://doi.org/10.1016/j.jvir.2013.01.007

Tan SYT, Ng KS, Tan C, Chuah M, Zhang M, Puar TH (2020) Bilateral aldosterone suppression in patients with right unilateral primary aldosteronism and review of the literature. J Endocr Soc 4(4):bvaa033. https://doi.org/10.1210/ jendso/bvaa033

Teng J, Hutchinson ME, Doery JC, Choy KW, Chong W, Fuller PJ, Yang J (2015) Role of adrenal vein sampling in primary aldosteronism: the Monash health experience. Intern Med J 45(11):1141-1146. https://doi.org/10.1111/imj.12873

Umakoshi H, Tsuiki M, Yokomoto-Umakoshi M, Takeda Y, Takashi Y, Kurihara I, Itoh H, Katabami T, Ichijo T, Wada N, Shibayama Y, Yoshimoto T, Ashida K, Ogawa Y, Kawashima J, Sone M, Inagaki N, Takahashi K, Watanabe M, Matsuda Y, Kobayashi H, Shibata H, Kamemura K, Otsuki M, Fujii Y, Yamamto K, Ogo A, Okamura S, Miyauchi S, Fukuoka T, Izawa S, Yanase T, Hashimoto S, Yamada M, Yoshikawa Y, Kai T, Suzuki T, Kawamura T, Naruse M (2018) Correlation between lateralization index of adrenal venous sampling and standardized outcome in primary aldosteronism. J Endocr Soc 2(8):893-902. https://doi.org/10.1210/js.2018-00055

Violari EG, Arici M, Singh CK, Caetano CM, Georgiades CS, Grady J, Tendler BR, Shichman SJ, Malchoff CD (2019) Adrenal vein sampling with and without cosyntropin stimulation for detection of surgically remediable aldosteronism. Endocrinol Diabetes Metab 2(2):e00066. https://doi.org/10.1002/edm2.66

Vonend O, Ockenfels N, Gao X, Allolio B, Lang K, Mai K et al (2011) Adrenal venous sampling: evaluation of the German Conn's registry. Hypertension 57(5):990-995. https://doi.org/10.1161/HYPERTENSIONAHA.110.168484

Webb R, Mathur A, Chang R, Baid S, Nilubol N, Libutti SK, Stratakis CA, Kebebew E (2012) What is the best criterion for the interpretation of adrenal vein sample results in patients with primary hyperaldosteronism? Ann Surg Oncol 19(6): 1881-1886. https://doi.org/10.1245/s10434-011-2121-5

Williams TA, Lenders JWM, Mulatero P, Burrello J, Rottenkolber M, Adolf C et al (2017) Outcomes after adrenalectomy for unilateral primary aldosteronism: an international consensus on outcome measures and analysis of remission rates in an international cohort. Lancet Diabetes Endocrinol 5(9):689-699. https://doi.org/10.1016/S2213-8587(17)30135-3

Wolley MJ, Gordon RD, Ahmed AH, Stowasser M (2015) Does contralateral suppression at adrenal venous sampling predict outcome following unilateral adrenalectomy for primary aldosteronism? A retrospective study. J Clin Endocrinol Metab 100(4):1477-1484. https://doi.org/10.1210/jc.2014-3676

Wu MH, Liu FH, Lin KJ, Sun JH, Chen ST (2019) Diagnostic value of adrenal iodine-131 6-beta-iodomethyl-19-norcholesterol scintigraphy for primary aldosteronism: a retrospective study at a medical center in North Taiwan. Nucl Med Commun 40(6):568-575. https://doi.org/10.1097/MNM. 0000000000000987

Zelinka T, Masek M, Vlkova J, Kasalicky M, Michalsky D, Holaj R et al (2012) Discrepant results of adrenal venous sampling in seven patients with primary aldosteronism. Kidney Blood Press Res 35(4):205-210. https://doi.org/10.1159/ 000330720

\section{Publisher's Note}

Springer Nature remains neutral with regard to jurisdictional claims in published maps and institutional affiliations.

\section{Submit your manuscript to a SpringerOpen ${ }^{\circ}$ journal and benefit from:}

- Convenient online submission

- Rigorous peer review

- Open access: articles freely available online

- High visibility within the field

- Retaining the copyright to your article

Submit your next manuscript at $\boldsymbol{\nabla}$ springeropen.com 